\title{
The Impact of Tunneled Pleural Catheters on the Quality of Life of Patients with Malignant Pleural Effusions
}

\author{
Natasha F. Sabur ${ }^{\mathrm{a}} \quad$ Alex Chee $^{\mathrm{a}} \quad$ David R. Stather $^{\mathrm{a}}$ Paul MacEachern ${ }^{\mathrm{a}}$ \\ Kayvan Amjadi ${ }^{b}$ Christopher A. Hergott ${ }^{c}$ Elaine Dumoulin ${ }^{d}$ Anne V. Gonzalez ${ }^{e}$ \\ Alain Tremblay ${ }^{\mathrm{a}}$ \\ a Department of Medicine, University of Calgary, Calgary, Alta., ${ }^{b}$ Department of Medicine, Univeristy of Ottawa, \\ Ottawa, Ont., 'Division of Respirology, Critical Care and Sleep Medicine, University of Saskatchewan, Saskatoon, \\ Sask., dDepartment of Medicine, University of Sherbrooke, Sherbrooke, Que., and 'Department of Medicine, McGill \\ University, Montreal, Que., Canada
}

\section{For editorial comment see p. 13}

\section{Key Words}

Malignant pleural effusion • Palliative care • Pleural catheter • Quality of life

\begin{abstract}
Background: Tunneled pleural catheters (TPC) are used in the management of malignant pleural effusions (MPE), but the impact of this palliative procedure on patient quality of life (QoL) has not been well described. Objectives: To ascertain the impact of TPCs on symptoms and QoL of patients with recurrent MPE. Methods: Patients with recurrent MPE completed the EORTC QLQ-C30 and LC13 QoL questionnaires at baseline, 2 and 14 weeks; FACIT-TS-G ${ }^{\odot}$ treatment satisfaction surveys were completed at 14 weeks. Results: $A$ total of 82 patients were recruited. Thirty-seven patients (37/82, 45\%) died prior to their 14-week follow-up appointment. Significant improvements in dyspnea at 2 weeks were demonstrated with both dyspnea scores (LC13 baseline score 64.1, 2-week score 43.7, mean change -20.4, $n=56, p<$ 0.001; C30 baseline score 78.9, 2-week score 46.6, mean change $-32.4, n=68, p<0.001)$, as well as with the MRC score (baseline median score 4, 2-week score 3, $n=70, p<0.001$ ).
\end{abstract}

Global health status/QoL was also significantly improved at 2 weeks (baseline score 34.1, 2-week score 46.3, mean change $12.3, n=68, p<0.001)$. Improvements in cough, fatigue and all functional scales were noted at 2 weeks. The improvements in dyspnea and global health status/QoL were maintained to 14 weeks in surviving subjects and there was further improvement in the MRC score at 14 weeks. Patients who completed the FACIT-TS-G survey demonstrated overall satisfaction with TPC treatment. Conclusions: TPCs are associated with a significant improvement in global health status, QoL and dyspnea at the 2-week time point in patients with recurrent MPE.

Copyright $\odot 2012$ S. Karger AG, Basel

\section{Introduction}

Malignant pleural effusion (MPE) is a common problem associated with advanced malignancy, with over $80 \%$ representing disseminated lung, breast and ovarian carcinomas, or lymphoma [1]. Dyspnea, found in over $50 \%$ of patients with MPE, is the most common and often the most distressing symptom [2]. Malignant effusions carry

\section{KARGER}

Fax +4161306 1234

E-Mail karger@karger.ch

www.karger.com (c) 2012 S. Karger AG, Basel

$0025-7931 / 13 / 0851-0036 \$ 38.00 / 0$

Accessible online at:

www.karger.com/res
Alain Tremblay, MDCM

University of Calgary

3330 Hospital Drive NW

Calgary AB T2N 4N1 (Canada)

E-Mail alain.tremblay@ucalgary.ca 
a grave prognosis, with a median survival estimated at merely 4-7 months [3, 4]. Management of MPE is therefore typically centered on palliation and symptom control.

Management options for MPE have traditionally included therapeutic thoracentesis, chemical and mechanical pleurodesis, pleuroperitoneal shunting and pleurectomy. Pleurodesis is considered the gold standard treatment and is typically achieved with a sclerosing agent such as doxycycline or talc. These agents act by inducing pleural inflammation, causing pleural fibrosis and subsequent pleurodesis [5]. However, this procedure has significant reported morbidity, with fever and severe chest discomfort commonly ensuing from the acute pleural injury required to achieve pleurodesis [6]. Talc slurry has been associated in some series with development of the acute respiratory distress syndrome, although a large study utilizing large particle talc did not encounter this complication $[7,8]$. In addition, talc pleurodesis generally necessitates a hospital stay of several days [9-12], an expensive and undesirable consequence for any palliative treatment in a patient population with such limited life expectancy.

In recent years, tunneled pleural catheters (TPC) have emerged as a viable alternative management strategy, although their role remains somewhat controversial. Indwelling pleural catheters have been shown to decrease effusion size [13], improve symptoms and even induce spontaneous pleurodesis, albeit in a delayed fashion [14]. TPCs have been shown to be effective in a broad population of patients, including those with trapped lung [1518]. TPCs are associated with minimal side effects and can be performed on an outpatient basis, and have recently been included in management guidelines as an acceptable alternative treatment for MPE [19]. However, the impact of tunneled pleural catheters on quality of life (QoL) has not been well studied. This study was designed to prospectively determine the impact of tunneled pleural catheters on symptoms and QoL of patients with recurrent, malignant pleural effusions, and to document patient satisfaction with this treatment modality.

\section{Materials and Methods}

\section{Study Design}

A prospective cohort study was designed to evaluate the impact of tunneled pleural catheters on patients with recurrent, malignant pleural effusions. This study was approved by the Research Ethics Board at each participating institution and written informed consent was obtained from all subjects.

\section{Study Participants}

All patients presenting to an interventional pulmonary service with a malignant pleural effusion at four tertiary hospitals across Canada were screened for inclusion into the study. Catheter insertion (PleurX catheter, CareFusion, San Diego, Calif., USA) and management took place as per previously published protocols [20].

Patients were considered eligible for the study if they were aged 18 or older, had a history of malignancy and had a recurrent, malignant pleural effusion that was symptomatic. In general, patients had undergone at least one therapeutic thoracentesis or other pleural drainage procedure demonstrating symptomatic improvement before they were considered appropriate candidates for TPC placement, although TPC may be used as the initial approach when patients are first seen in a clinic with large symptomatic effusions. A physician or study nurse explained the study to each patient. Those who agreed to have a TPC inserted and consented to the study were enrolled. Patients received treatment of their primary tumor through their medical and radiation oncologists as per standard guidelines and local protocols.

Patients were not eligible for participation if prior chemical pleurodesis had been carried out on the side of the symptomatic effusion. Active pleural or pulmonary infection or current hospitalization for any reason other than a symptomatic MPE were criteria for exclusion from study participation. Patients who were anticipated to have a life expectancy of less than 3 months and those who could not complete the questionnaires were also excluded. The survey was available in both English and French.

\section{Data Collection}

Basic demographic information including age, gender and type of malignancy were collected at baseline. Patients completed the European Organization for Research and Treatment of Cancer Quality of Life questionnaire (EORTC QLQ-C30 Version 3.0) and lung cancer module (LC13) prior to catheter insertion [21]. The treating physician (respirologist) recorded the patient's MRC dyspnea score and estimated the percent of the hemithorax occupied with pleural fluid based on the chest radiograph.

At the 2-week and 14-week clinic visits, patients completed the EORTC QLQ-C30 and LC13 questionnaires. The treating physician again assessed the MRC dyspnea score, estimated the percent of the hemithorax occupied and recorded any problems or complications associated with the TPC. At the 14-week visit, patients also completed the Functional Assessment of Chronic Illness Therapy Treatment Satisfaction questionnaire (FACIT-TS-G ${ }^{\odot}$ version 1.0). If the TPC was removed prior to the 14 -week visit, patients were asked to complete the 14 -week surveys at the time of removal. Questionnaires were mailed to patients who were unable to attend scheduled appointments.

\section{Outcome Measurements}

The primary outcome measure was the dyspnea score (LC13 and C30) at 2 weeks. Secondary outcome measures included global health status/QoL score at 2 and 14 weeks; LC13 and C30 dyspnea scores at 14 weeks; FACIT-TS-G scores; MRC scores; other symptoms scores (fatigue, cough, chest pain) at 2 weeks and functional scales (physical, social, emotional) at 2 weeks. 
QoL Assessment

The EORTC QLQ-C30 and LC13 questionnaires are composed of single- and multi-item scales. All questions are presented on a Likert-type scale (answer options from 1 to 4 or 1 to 7 ). The raw scores are linearly transformed into composite scores, which are reported from 0 to 100 . For symptom scales, such as the dyspnea score, a higher value represents a higher level of symptomatology; for functional scales, such as physical function, and the global health status/QoL scale, a higher score represents a higher level of function and a better QoL [22]. A difference of 5-10 represents a small change, $10-20$ points represents a moderate change and greater than 20 points indicates a large change [23].

The FACIT-TS-G treatment satisfaction questionnaire is also composed of single and multi-item scales, answered on a Likert scale (0-2 or 0-4). Data on treatment satisfaction and recommendation can be transformed into composite values, which are reported from 0 to 100. All remaining items are evaluated with descriptive statistics.

\section{Statistical Analysis}

Sample size calculations were performed with a paired t test, using an alpha of 0.025 to account for two comparison points (2 weeks and 14 weeks), and a beta of 0.8 with SD of 20 . In order to see a change in at least 10 points in the EORTC dyspnea score, we estimated a sample size of 40 ; however, to account for patient mortality and those lost to follow-up, our target sample size was doubled to 80 .

Data are presented as means \pm SD unless otherwise specified. Dyspnea scores, global health status/QoL score and the remaining symptom and functional scores from baseline to 2 weeks were analyzed using paired t tests. Repeated measures ANOVA analysis was performed to compare dyspnea scores and the global health status/QoL score between baseline, 2 and 14 weeks. MRC scores were analyzed using Wilcoxon signed-rank tests. Treatment satisfaction data are presented as means, with overall treatment rating and effectiveness reported with descriptive statistics. $p$ values $<0.05$ were considered significant. All data were analyzed with the use of the SPSS software package (version 19.0; SPSS Inc., Chicago, Ill., USA).

\section{Results}

Eighty-two subjects were recruited into the study from the four participating centers. Cohort demographics are detailed in table 1 . The mean age of participants was 67 years. The most common tumor type was primary lung cancer (46\%), followed by breast cancer (15\%). Prior pleural procedures performed are listed in table 1, with subjects having undergone a mean of 2.1 thoracenteses prior to TPC insertion. Nineteen patients achieved pleurodesis and had their TPC removed prior to the 14-week appointment (23\%), with a mean of 54 days to TPC removal (table 2). There was a greater than $25 \%$ reduction in the percent hemithorax occupied by pleural fluid 2 weeks following placement of a TPC ( $55 \%$ hemithorax occupied at
Table 1. Patient characteristics $(\mathrm{n}=82)$

\begin{tabular}{lc}
\hline Mean age (range), years & $67(41-95)$ \\
Sex & $45(55 \%)$ \\
Female & $37(45 \%)$ \\
Male & \\
Inpatient vs. outpatient & $19(25 \%)$ \\
Inpatient & $59(75 \%)$ \\
Outpatient & \\
Tumor type & $36(46 \%)$ \\
Lung & $12(15 \%)$ \\
Breast & $5(6 \%)$ \\
Ovarian & $9(11 \%)$ \\
Mesothelioma & $17(22 \%)$ \\
Other & \\
Pleural fluid cytology & $51(77 \%)$ \\
Positive & $15(23 \%)$ \\
Negative & \\
Procedures prior to TPC & $62(75.6 \%)$ \\
Thoracentesis only & $5(6.1 \%)$ \\
Chest tube & $2(2.4 \%)$ \\
Thoracoscopy or VATS & $2(2.4 \%)$ \\
Prior TPC & $11(13.4 \%)$ \\
None recorded &
\end{tabular}

Table 2. Patient outcomes

$\begin{array}{ll}\text { TPC removal } & 19(23 \%) \\ \text { Days to removal (range) } & 54(28-90) \\ \text { Death by } 14 \text { weeks } & 37(45 \%) \\ \text { Complications } & \\ \quad \text { Cellulitis } & 4(4.8 \%) \\ \quad \text { Empyema } & 1(1.2 \%) \\ \quad \text { Loculation } & 3(3.6 \%)\end{array}$

baseline, 27\% hemithorax occupied at 2 weeks, change $28 \%, \mathrm{p}=0.001)$. Thirty-seven patients $(37 / 82,45 \%)$ died prior to their 14-week follow-up appointment. Complications related to the indwelling catheters were rare, and are outlined in table 2 .

Results of the primary and secondary outcome measures are detailed in table 3 . Statistically and clinically significant improvements in global health status/overall QoL were noted at the 2-week time point (baseline score 34.1, 2 -week score 46.3, mean change 12.3, $\mathrm{n}=68, \mathrm{p}<0.001$ ). Improvements in dyspnea from baseline to week 2 were also demonstrated with both the LC13 (baseline score 64.1, 2 -week score 43.7, mean change $-20.4, \mathrm{n}=56, \mathrm{p}<0.001$ ) and the C30 (baseline score 78.9, 2-week score 46.6, mean change $-32.4, \mathrm{n}=68, \mathrm{p}<0.001)$ dyspnea scales, as well as 

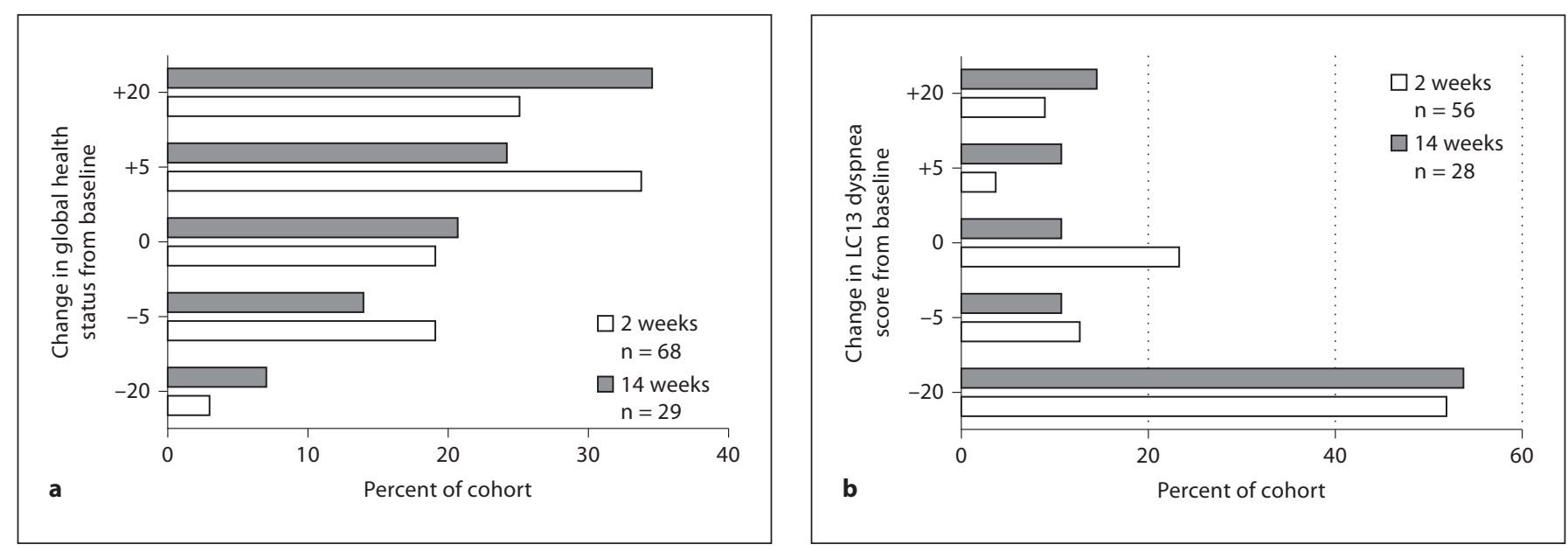

Fig. 1. Percentage of patients with clinically significant changes in global QoL and dyspnea scores. a Global health status (a higher score represents improved QoL). b LC13 dyspnea score (a lower score represents decreased symptoms). A change of 5 points is considered a mild but clinically significant difference and a 20-point change is considered a large difference.

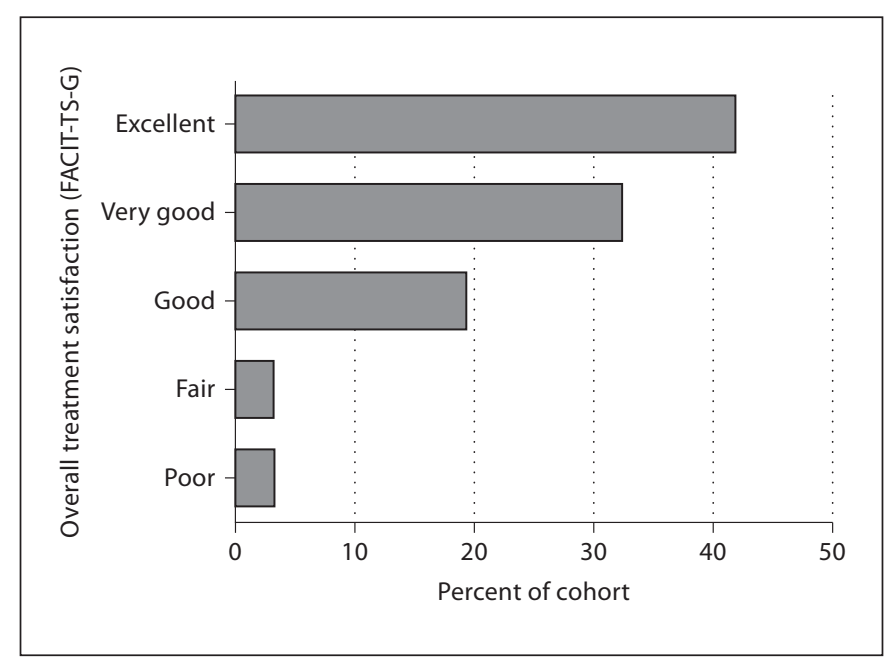

Fig. 2. Patient evaluation of TPC treatment (FACIT-TS-G). Evaluation of TPC treatment was done at the final 14-week visit or at the time of TPC removal. Patients were asked to rate the effectiveness of the treatment and to provide a rating of their overall treatment experience.

with the MRC score (baseline median score 4, 2-week score 3, $\mathrm{n}=70, \mathrm{p}<0.001)$. Improvements in QoL and dyspnea were noted in the subgroup of subjects with lung cancer as well as in those with other primary tumors. The percentage of subjects with clinically significant changes in dyspnea and overall QoL is demonstrated in figure 1.
Improvements in cough (baseline score 54.2, 2-week score 38.8 , mean change $-15.4, \mathrm{n}=67, \mathrm{p}<0.001)$ and fatigue (baseline score 64.4, 2-week score 51.8, mean change $-12.6, \mathrm{n}=70, \mathrm{p}<0.001$ ) also occurred and no worsening of chest pain was noted (baseline score 25.8, 2-week score 24.2 , mean change $-1.5, \mathrm{n}=66, \mathrm{p}=0.626$ ). All three functional scales (physical function +5.8 , emotional function +7.8 and social function +9.3 ) were also improved at 2 weeks $(\mathrm{p}<0.05)$. The improvements in dyspnea and global health status/QoL continued to 14 weeks in surviving subjects (table 3 ) and there was a further improvement in the MRC score at 14 weeks. Patients who completed the FACIT-TS-G survey demonstrated overall satisfaction with TPC treatment (table 4), with over $75 \%$ rating it as very good or excellent (fig. 2).

\section{Discussion}

This study demonstrates the positive impact of tunneled pleural catheters on dyspnea, cough and fatigue, as well as functional status and overall QoL in patients with malignant pleural effusions. To our knowledge, this is the first study to evaluate both symptoms and QoL in this population using questionnaires that have been validated in patients with cancer. In addition, our study demonstrates that the responsiveness of the EORTC QLQ-C30 and LC13 measurement tools can be used to monitor treatment-related changes in this disease. 
Table 3. Outcome measures at all 3 time points

\begin{tabular}{lrrr}
\hline & Baseline & 2 weeks & 14 weeks \\
\hline Global health status/QoL $^{\mathrm{a}}$ & $33.9(\mathrm{n}=80)$ & $46.2^{\mathrm{b}}(\mathrm{n}=70)$ & $53.1^{\mathrm{b}}(\mathrm{n}=30)$ \\
C30 dyspnea score $^{\mathrm{a}}$ & $79.8(\mathrm{n}=81)$ & $46.9^{\mathrm{b}}(\mathrm{n}=69)$ & $36.6^{\mathrm{b}}(\mathrm{n}=31)$ \\
LC13 dyspnea score $^{\mathrm{a}}$ & $63.6(\mathrm{n}=73)$ & $43.6^{\mathrm{b}}(\mathrm{n}=63)$ & $32.3^{\mathrm{b}}(\mathrm{n}=31)$ \\
MRC score $^{\mathrm{c}}$ & $4(\mathrm{n}=78)$ & $3^{\mathrm{d}}(\mathrm{n}=71)$ & $2^{\mathrm{d}}(\mathrm{n}=35)$ \\
\hline
\end{tabular}

$\mathrm{n}$ represents the number of patients with available data for each score at each time point.

${ }^{a} \mathrm{p}<0.05$, repeated measures ANOVA analysis was performed on patients with data available at all 3 time points, data presented in means.

${ }^{\mathrm{b}} \mathrm{p}<0.05$, paired $\mathrm{t}$ test vs. baseline.

${ }^{c} \mathrm{p}<0.05$, Friedman statistic performed on patients with data available at all 3 time points; data presented in medians.

${ }^{\mathrm{d}} \mathrm{p}<0.05$, Wilcoxon signed-rank test vs. baseline.

QoL in patients treated for malignant pleural effusions has not been extensively studied. Several small case series evaluating treatments for MPE have addressed the question of QoL using measures such as visual analogue scales [10], telephone questionnaires [15], or in the form of a simple question posed to patients following the intervention. One case series reported an improvement in QoL in $34 / 34$ patients surveyed with a single question [16]; another small series described an improvement in overall 'well-being' after placement of a TPC in 12/12 patients [24]. Putnam et al. [12] used the dyspnea component of the Guyatt Chronic Respiratory Questionnaire to address QoL issues, and were able to demonstrate an improvement in QoL at 30, 60 and 90 days post-TPC compared to baseline. However, that questionnaire has only been validated in patients with airflow obstruction, and never in patients with malignancy [25]. A recent study by Davies et al. [26] used the EORTC QLQ-C30 scale to assess QoL as a secondary endpoint in 52 patients, and found an overall improvement in QoL 6 weeks after TPC placement.

Many more studies have attempted to evaluate the impact of TPCs on symptoms, particularly dyspnea, as a surrogate for QoL, although most have not applied validated scoring tools. A case series of 250 procedures graded improvements in dyspnea on a 3-point scale (complete, partial, absent) and demonstrated a partial or complete improvement in $88.8 \%$ of patients treated with TPCs [13]. Putnam et al. [12] reported an improvement in dyspnea using the Borg dyspnea scale, while Davies et al. [26] demonstrated improvements in dyspnea and chest pain using visual analogue scales. Other studies have simply reported 'decrease in dyspnea' [24] or 'symptomatic im-
Table 4. Treatment satisfaction and recommendation (FACITTS-G)

\begin{tabular}{ll}
\hline & Mean score \pm SD \\
\hline Treatment satisfaction & $81.8 \pm 24.8$ \\
Treatment recommendation & $96.0 \pm 15.9$ \\
\hline
\end{tabular}

Data were collected at 14 weeks or at the time of TPC removal. Treatment satisfaction questions were: Do you feel you received the treatment that was right for you? Are you satisfied with the effects of this treatment so far? Treatment recommendation questions were: Would you recommend this treatment to others with your illness? Would you choose this treatment again?

provement' [15] with TPCs. A meta-analysis of nineteen studies reported symptomatic improvements in $95.6 \%$ of patients following TPC placement [14], although none of the studies included examined QoL using standardized tools.

We chose to use the European Organization for the Research and Treatment of Cancer quality of life questionnaire as this survey was developed specifically for clinical trials in oncology and has been validated and tested in a wide variety of cancer populations [27, 28]. This questionnaire has been used to monitor treatment response in many different tumor types; it has also been used to investigate the relationship between QoL and various other factors such as prognosis [29].

The EORTC survey has been used to evaluate pretreatment QoL in a number of cancer populations. One large study evaluating pretreatment QoL indices in almost 
1,200 patients with various stages of non-small cell lung cancer found a mean QoL score of 53 in patients with both localized and metastatic disease, with C30 dyspnea scores ranging between 36 and 40 [30]. Another study in just over 1,000 patients with breast cancer at various stages of disease cited a mean QoL score of 65 [31], while in patients with brain, bone and lung metastases assessed prior to palliative radiation therapy, scores ranged between 48 and 61 [32]. Compared to this, our study patients had significantly lower baseline QoL scores (33.9) and were significantly more dyspneic (79.8). Other studies in patients with MPE have shown similar QoL (36.537) and dyspnea (79.7) scores prior to therapeutic interventions $[26,33]$. This highlights the significant morbidity associated with malignant pleural effusions above and beyond that associated with advanced, metastatic disease. However, following placement of a TPC and regular drainage of fluid at the 2-week time point, our study patients had QoL and dyspnea scores more comparable to the pretreatment scores of both non-small cell lung cancer patients and oncology patients receiving palliative treatments.

The impacts of various other oncologic treatments on QoL have been investigated using the EORTC questionnaires. High-dose radiation therapy in lung cancer patients actually decreased the QoL score by almost 5 points and increased dyspnea scores by 5 points 2 weeks after radiation therapy, although this decline did not persist beyond 3 months [34]. Patients with metastatic solid tumors receiving palliative chemotherapy had an improvement of 8 points in their QoL scores after several rounds of chemotherapy [35]. The most remarkable improvement in dyspnea scores has been demonstrated in patients receiving bronchoscopic intervention for malignant airway obstruction, with improvements of 9 points in the QoL scores and almost 40 points on the C30 dyspnea scale 30 days after stent placement [36]. In our study, patients had a mean improvement of 12 points in the QoL scale and improvements of 20-30 points on the dyspnea scales only 2 weeks after the intervention, a significant improvement in relation to many other palliative treatments.

Although the FACIT-TS-G survey has not been widely studied in other cancer populations, our study results demonstrate that the majority of patients who received TPCs were satisfied with their treatment. Most patients felt that the treatment was right for them and would recommend it to other patients with malignant pleural effusions.
The main limitation of this study is the observational nature of our cohort, with no other treatment group against which to directly compare our results. A high patient mortality rate also significantly restricted our cohort over time, with nearly half of our patients lost from the study by 14 weeks. This is an unfortunate but unavoidable limitation of studies performed in any palliative patient group, perhaps necessitating a shorter followup time period for patient re-evaluation. Nevertheless, the fact that improvements in outcome measurements were reflected at both the 2 - and 14 -week time points suggests that the changes we demonstrate are real and not simply the result of a healthy survivor effect. Finally, the EORTC-C30 questionnaire was lengthy and time consuming to complete, and skipped questions affected the calculation of composite scores for analysis. Future studies evaluating QoL scales in this population may choose to use the EORTC-C15-PAL survey, a shorter core questionnaire designed specifically for palliative care cancer patients [37].

Tunneled pleural catheters are slowly being integrated into the care strategy of patients with malignant pleural effusions in many centers around the world and are now included in international treatment guidelines for management of MPE [19]. Our study adds validity to the current literature suggesting that TPCs are well tolerated and that they significantly improve patient symptoms and QoL. Goals for care in this palliative patient group should place maximal importance on symptom control and QoL, and prioritize treatment strategies that can be offered on an outpatient basis with minimal complications.

\section{Financial Disclosure and Conflicts of Interest}

Dr. Tremblay has received consulting fees from CareFusion Inc. Dr. Tremblay holds a patent pending on a method to treat malignant pleural effusions. None of the remaining authors have any conflicts of interest.

Funding for this work was received from the University of Calgary Department of Medicine Research Development Fund. 


\section{References}

1 Sahn SA: Malignancy metastatic to the pleura. Clin Chest Med 1998;19:351-361.

$\checkmark 2$ Chernow B, Sahn SA: Carcinomatous involvement of the pleura: an analysis of $96 \mathrm{pa}-$ tients. Am J Med 1977;63:695-702.

3 Heffner JE, Nietert PJ, Barbieri C: Pleural fluid $\mathrm{pH}$ as a predictor of survival for patients with malignant pleural effusions. Chest 2000;117:79-86.

4 Pilling JE, Dusmet ME, Ladas G, Goldstraw P: Prognostic factors for survival after surgical palliation of malignant pleural effusion. J Thorac Oncol 2010;5:1544-1550.

5 Rodriguez-Panadero F, Montes-Worboys A: Mechanisms of pleurodesis. Respiration 2012;83:91-98.

6 6 Lee YC, Baumann MH, Maskell NA, Waterer GW, Eaton TE, Davies RJ, et al: Pleurodesis practice for malignant pleural effusions in five English-speaking countries: survey of pulmonologists. Chest 2003;124:2229-2238.

7 Rehse DH, Aye RW, Florence MG: Respiratory failure following talc pleurodesis. Am J Surg 1999;177:437-440.

-8 Janssen JP, Collier G, Astoul P, Tassi GF, Noppen M, Rodriguez-Panadero F, et al: Safety of pleurodesis with talc poudrage in malignant pleural effusion: a prospective cohort study. Lancet 2007;369:1535-1539.

$\checkmark 9$ Aelony Y, Yao JF: Prolonged survival after talc poudrage for malignant pleural mesothelioma: case series. Respirology 2005; 10 : 649-655.

10 Diacon AH, Wyser C, Bolliger CT, Tamm M, Pless M, Perruchoud AP, et al: Prospective randomized comparison of thoracoscopic talc poudrage under local anesthesia versus bleomycin instillation for pleurodesis in malignant pleural effusions. Am J Respir Crit Care Med 2000;162:1445-1449.

- 11 Arapis K, Caliandro R, Stern JB, Girard P, Debrosse D, Gossot D: Thoracoscopic palliative treatment of malignant pleural effusions: results in 273 patients. Surg Endosc 2006;20:919-923.

-12 Putnam JB Jr., Light RW, Rodriguez RM, Ponn R, Olak J, Pollak JS, et al: A randomized comparison of indwelling pleural catheter and doxycycline pleurodesis in the management of malignant pleural effusions. Cancer 1999;86:1992-1999.

13 Tremblay A, Michaud G: Single-center experience with 250 tunnelled pleural catheter insertions for malignant pleural effusion. Chest 2006;129:362-368.

14 Van Meter ME, McKee KY, Kohlwes RJ: Efficacy and safety of tunneled pleural catheters in adults with malignant pleural effusions: a systematic review. J Gen Intern Med 2011;26:70-76.
-15 Efthymiou CA, Masudi T, Thorpe JAC, Papagiannopoulos K: Malignant pleural effusion in the presence of trapped lung: fiveyear experience of PleurX tunnelled catheters. Interact Cardiovasc Thorac Surg 2009; 9:961-964.

16 Ohm C, Park D, Vogen M, Bendick P, Welsh $R$, Pursel S, et al: Use of an indwelling pleural catheter compared with thorascopic talc pleurodesis in the management of malignant pleural effusions. Am Surg 2003;69:198-202.

17 Pien GW, Gant MJ, Washam CL, Sterman DH: Use of an implantable pleural catheter for trapped lung syndrome in patients with malignant pleural effusion. Chest 2001;119: 1641-1646.

18 Qureshi RA, Collinson SL, Powell RJ, Froeschle PO, Berrisford RG: Management of malignant pleural effusion associated with trapped lung syndrome. Asian Cardiovasc Thorac Ann 2008;16:120-123.

19 Roberts ME, Neville E, Berrisford RG, Antunes G, Ali NJ, Group BTSPDG: Management of a malignant pleural effusion: British Thoracic Society Pleural Disease Guideline 2010. Thorax 2010;65(suppl 2):ii32-ii40.

20 MacEachern P, Stather D, Tremblay A: Tunelled pleural catheters; in Beamis JF Mathur P, Mehta AC (eds): Interventional Pulmonary Medicine, ed 2. New York, Informa Healthcare, 2009.

-21 Aaronson NK, Ahmedzai S, Bergman B, Bullinger M, Cull A, Duez NJ, et al: The European Organization for Research and Treatment of Cancer QLQ-C30: a quality-oflife instrument for use in international clinical trials in oncology. J Natl Cancer Inst 1993;85:365-376.

22 Fayers PM Aaronson NK, Bjordal K, Groenvold $\mathrm{M}$, Curran D, Bottomley A, on behalf of the EORTC Quality of Life Group: The EORTC QLQ-C30 Scoring Manual (ed 3). Brussels, European Organisation for Research and Treatment of Cancer, 2001.

-23 Osoba D, Rodrigues G, Myles J, Zee B, Pater $\mathrm{J}$ : Interpreting the significance of changes in health-related quality-of-life scores. J Clin Oncol 1998;16:139-144.

24 van den Toorn LM, Schaap E, Surmont VFM, Pouw EM, van der Rijt KCD, van Klaveren RJ: Management of recurrent malignant pleural effusions with a chronic indwelling pleural catheter. Lung Cancer 2005;50:123127.

25 Guyatt GH, Berman LB, Townsend M, Pugsley SO, Chambers LW: A measure of quality of life for clinical trials in chronic lung disease. Thorax 1987;42:773-778.

26 Davies HE, Mishra EK, Kahan BC, Wrightson JM, Stanton AE, Guhan A, et al: Effect of an indwelling pleural catheter vs. chest tube and talc pleurodesis for relieving dyspnea in patients with malignant pleural effusion: the TIME2 randomized controlled trial. JAMA 2012;307:1-7.
27 Groenvold M, Klee MC, Sprangers MA, Aaronson NK: Validation of the EORTC QLQC30 quality of life questionnaire through combined qualitative and quantitative assessment of patient-observer agreement. J Clin Epidemiol 1997;50:441-450.

28 Hjermstad MJ, Fossa SD, Bjordal K, Kaasa S: Test/retest study of the European Organization for Research and Treatment of Cancer Core Quality-of-Life Questionnaire. J Clin Oncol 1995;13:1249-1254.

29 Mauer ME, Taphoorn MJ, Bottomley A, Coens C, Efficace F, Sanson M, et al: Prognostic value of health-related quality-of-life data in predicting survival in patients with anaplastic oligodendrogliomas, from a phase III EORTC brain cancer group study. J Clin Oncol 2007;25:5731-5737.

30 Braun DP, Gupta D, Staren ED: Quality of life assessment as a predictor of survival in non-small cell lung cancer. BMC Cancer 2011;11:353.

31 Hoyer M, Johansson B, Nordin K, Bergkvist L, Ahlgren J, Lidin-Lindqvist A, et al: Healthrelated quality of life among women with breast cancer - a population-based study. Acta Oncol 2011;50:1015-1026.

32 Caissie A, Culleton S, Nguyen J, Zhang L, Zeng L, Holden L, et al: EORTC QLQ-C15PAL quality of life scores in patients with advanced cancer referred for palliative radiotherapy. Support Care Cancer 2012;20:841848.

33 Schniewind B, Rose T, Woltmann N, Walter J, Becker T, Dohrmann P, et al: Clinical outcomes and health-related quality of life after thoracoscopic talc pleurodesis. J Palliat Med 2012;15:37-42.

34 Pijls-Johannesma M, Houben R, Boersma L, Grutters J, Seghers K, Lambin P, et al: Highdose radiotherapy or concurrent chemo-radiation in lung cancer patients only induces a temporary, reversible decline in QoL. Radiother Oncol 2009;91:443-448.

- 35 Bang SM, Park SH, Kang HG, Jue JI, Cho IH, Yun YH, et al: Changes in quality of life during palliative chemotherapy for solid cancer. Support Care Cancer 2005;13:515-521.

36 Oviatt PL, Stather DR, Michaud G, MacEachern P, Tremblay A: Exercise capacity, lung function, and quality of life after interventional bronchoscopy. J Thorac Oncol 2011;6: $38-42$.

37 Groenvold M, Petersen MA, Aaronson NK, Arraras JI, Blazeby JM, Bottomley A, et al: The development of the EORTC QLQ-C15PAL: a shortened questionnaire for cancer patients in palliative care. Eur J Cancer 2006; 42:55-64. 